\title{
THE
}

UNIVERSITY

University of Rhode Island

OF RHODE ISLAND

DigitalCommons@URI

Graduate School of Oceanography Faculty

Publications

Graduate School of Oceanography

$11-8-2013$

\section{Field Calibration of Low Density Polyethylene Passive Samplers for Gaseous POPs}

Mohammed A. Khairy

Rainer Lohmann

University of Rhode Island, rlohmann@uri.edu

Follow this and additional works at: https://digitalcommons.uri.edu/gsofacpubs

The University of Rhode Island Faculty have made this article openly available.

Please let us know how Open Access to this research benefits you.

This is a pre-publication author manuscript of the final, published article.

Terms of Use

This article is made available under the terms and conditions applicable towards Open Access

Policy Articles, as set forth in our Terms of Use.

Citation/Publisher Attribution

Khairy, M.A., \& Lohmann, R. (2013). Field calibration of low density polyethylene passive samplers for gaseous POPs. Environmental Science: Processes and Impacts. doi: 10.1039/C3EM00493

Available at: http://dx.doi.org/10.1039/C3EM00493G

This Article is brought to you for free and open access by the Graduate School of Oceanography at DigitalCommons@URI. It has been accepted for inclusion in Graduate School of Oceanography Faculty Publications by an authorized administrator of DigitalCommons@URI. For more information, please contact digitalcommons-group@uri.edu. 


\title{
Field Calibration of Low Density Polyethylene Passive Samplers for Gaseous POPs
}

\author{
Mohammed A. Khairy $^{\dagger * a}$, Rainer Lohmann ${ }^{\text {a }}$
}

${ }^{a}$ Graduate School of Oceanography, University of Rhode Island, 215 South Ferry Road, Narragansett, Rhode Island 02882, United States

${ }^{\dagger}$ Permanent address: Department of Environmental Sciences, Faculty of Science, Alexandria University, 21511 Moharam Bek, Alexandria, Egypt

*Corresponding author. E-mail address: mohammed_khairy77@yahoo.com

Phone: 401-874-6765; Fax 401-874-6811

\begin{abstract}
A field calibration study of low density polyethylene (LDPE) for measuring atmospheric concentrations of persistent organic pollutants (POPs) was performed in East Providence (RI), USA. LDPE samplers were collected after 3, 7, 10, 14, 17 and 21 days of exposure along with samples from a co-deployed high volume sampler. Uptake kinetics of POPs by LDPEs were confirmed both by using an uptake study over time and the inclusion of performance reference compounds (PRCs). Results indicated that only POPs with log sampler-air partitioning coefficient $\left(\mathrm{K}_{\mathrm{PE}-\mathrm{A})} \leq 7.6\right.$ were approaching equilibrium by the end of the deployment period, whereas all the other POPs were still in the linear uptake rate. Sampling rates $\left(1.0-80 \mathrm{~m}^{3} / \mathrm{d}\right)$ were higher for some POPs when compared to literature values possibly due to the open sampler housing design used. Derived $\mathrm{K}_{\mathrm{PE}-\mathrm{A}} \mathrm{S}$ for the detected POPs in field calibration study were correlated against the compounds' octanol-air partitioning coefficients $\left(\log \mathrm{K}_{\mathrm{OA}}\right):\left[\log \mathrm{K}_{\mathrm{PE}-\mathrm{A}}=0.88 \pm 0.02 * \log \mathrm{K}_{\mathrm{OA}}+\right.$ $\left.0.40 \pm 0.21\left(\mathrm{R}^{2}=0.96 ; \mathrm{n}=59 ; \mathrm{SE}=0.23\right)\right]$, and their subcooled liquid vapour pressures $\left(\log \mathrm{P}_{\mathrm{L}}\right.$, in units?): $\left[\log \mathrm{K}_{\mathrm{PE}-\mathrm{A}}=-0.82 \pm 0.02 * \log \mathrm{P}_{\mathrm{L}}+6.22 \pm 0.05\left(\mathrm{R}^{2}=0.96 ; \mathrm{n}=59 ; \mathrm{SE}=\right.\right.$
\end{abstract}


0.22)] to predict values for all POPs. $\mathrm{P}_{\mathrm{L}}$ was generally found to be a better predictor of $\mathrm{K}_{\mathrm{PE}-\mathrm{A}}$ for all POPs.

\section{Keywords: LDPE, PRCs, uptake kinetics, sampling rates, $\mathrm{K}_{\mathrm{PE}-\mathrm{A}}$}

\section{1- Introduction}

High volume air samplers have been used for years to monitor concentrations of persistent organic pollutants (POPs). Most monitoring programs still rely on active sampling for measuring atmospheric POPs. Yet high-volume samplers need maintenance, a power supply and a trained operator, and the sampling unit itself is bulky making it inappropriate for usage in remote areas ${ }^{1-3}$. They are also relatively expensive, which limits their applicability in large scale sampling campaigns where concurrent samples are collected $^{1,4}$. Accordingly, atmospheric monitoring of POPs was either not performed in many developing countries worldwide ${ }^{5,6}$ or tend to be restricted to a small number of sites even in the large atmospheric monitoring campaigns such as the Integrated Atmospheric Deposition Network (IADN) around the Great Lakes ${ }^{1}$.

To solve the problem, passive sampling techniques have been developed in response to the growing need for inexpensive and simple monitoring of atmospheric POPs. The basic theory underlying the accumulation of POPs in passive air samplers is via diffusion and absorption into the sampler matrix ${ }^{7}$. Natural passive samplers such as plant leaves have been used for monitoring atmospheric $\mathrm{POPs}^{8-10}$. However, inconsistency in contaminant uptake rates, high biological variability and variable exposure times may all make interpretation very difficult. 
Synthetic passive air samplers have proven to be a powerful monitoring technique for POPs as they are cheaper and require less labour compared to active samplers ${ }^{11-15}$. By using passive samplers, more measurements can be undertaken to establish spatial and temporal trends at reduced cost. Yet many substances measured with passive sampling do not reach equilibrium during the exposure period. Ideally, this requires an in-situ calibration of the uptake process, though programs such as the Global Atmosphere Passive Sampling (GAPS) often rely on typical sampling rates. However, the major advantage is that a time-integrated concentration is obtained that can be used for compliance checking with air quality guidelines.

Different matrices have been utilized as passive samplers for monitoring atmospheric concentrations of POPs. Semipermeable membrane devices (SPMDs) were first demonstrated to be a good passive sampling medium ${ }^{12,14,16}$. Polyurethane foam (PUF) disks were then introduced and are currently the most widely used passive samplers for monitoring atmospheric $\mathrm{POPs}^{2,3,15,17,18}$. XAD-2 resin passive samplers were also introduced lately and were used for monitoring atmospheric concentrations of organochlorine pesticides $(\mathrm{OCPs})^{1,19}$. Other passive air samplers were developed ${ }^{13,20,21}$ but their use in the field is less reported in the literature.

In recent years, low density polyethylene sheets (LDPE) have been used for monitoring of atmospheric PAHs ${ }^{5,7,21,22}$ and OCPs $^{6}$. LDPE sheets are essentially SPMD samplers without triolein filling. As compared to other matrices for passive sampling, LDPE is the simplest (in its chemical makeup), cheapest polymer available ${ }^{23}$ and easy to deploy. Target analytes can be easily extracted from the PE matrix on the bench, and generally 
without further cleanup of the extracts (except for dioxins and furans). The sampler is versatile because it can be operated in the uptake (kinetic) or equilibrium (thermodynamic) sampling mode by varying the thickness of the PE and the exposure time (days, weeks and months). The basic theory underlying the accumulation of POPs in passive air samplers via diffusion and absorption into the sampler matrix has been detailed previously ${ }^{22}$ (see text SI 1 for more details).

LDPE has been previously validated as passive air samplers for $\mathrm{PAHs}^{5,22}$ and $\mathrm{OCPs}^{6}$. However, there is as of yet, no generalizable correlation that would allow the use of LDPEs across a wide range of organic contaminants. Being able to predict partitioning constants to LDPE for most POPs would enable the increased utilization of LDPE as a passive air sampler. In particular, we need to better understand uptake kinetics and equilibration times of atmospheric POPs in LDPE to accurately determine the appropriate deployment periods and predict vapour phase atmospheric concentrations.

The purpose of the current study was to calibrate the LDPE passive air samplers against the conventional active high-volume sampler by targeting 25 different OCPs, 29 PCB congeners and $12 \mathrm{PBDE}$ congeners simultaneously. In particular, our goals were to (i) derive more information on field-based uptake rates; (ii) define the equilibrium times of POPs in the samplers; (iii) calculate sampler-air partitioning coefficients for the investigated POPs; and (iv) derive a general correlation enabling the calculation of LDPE-air partition constants based on easily available physico-chemical properties. For that purpose, LDPEs were deployed in East Providence (RI), USA (NovemberDecember, 2012), while continuous active samples were collected concurrently. 


\section{2- Materials and methods}

\section{1- Field Calibration Study Design}

To determine uptake kinetics and equilibration times for POPs, 14 LDPEs were deployed at an air monitoring site in East Providence, USA (Figure SI 1) from November to December, 2012. Two samplers each were collected after 3, 7, 10, 14 and 17 days of deployment and the remainder were collected after 21 days. To predict $\mathrm{K}_{\mathrm{PE}-\mathrm{A}} \mathrm{S}$ for the investigated POPs, a high volume sampler (TE-PNY-1123, Tisch Environmental, USA) was deployed alongside the passive samplers in East Providence to collect samples at the same time intervals (for meteorological details and sampling volumes, see Table SI 1).

\subsection{Preparation and Deployment of LDPEs}

LDPE sheets were cut from commercial sheeting (Carlisle Plastics, Inc., Minneapolis, MN) with a thickness of $51 \mu \mathrm{m}$, yielding a $10 \times 30 \mathrm{~cm}$ strip of $\sim 1-2 \mathrm{~g}$ each. Samplers were then cleaned with DCM and n-hexane and each 12-14 samplers were spiked with four PRCs at a nominal concentration of $1 \mu \mathrm{g}$ per sampler according to Booij et al. ${ }^{24}$. Selected PRCs were 2,5-dibromobiphenyl (PBB 9), 2,2',5,5'-tetrabromobiphenyl (PBB 52), 2,2',4,5',6-pentabromobiphenyl (PBB 103) and octachloronaphthalene (OCN). Once spiked, PEs were strung on stainless steel wires, placed in precleaned aluminum foil packets, numbered, and frozen in plastic bags until the time of deployment. LDPE sheets were deployed at the roof of the monitoring site (Figure SI 1) 3 meters above the ground surface. Each LDPE was kept inside a dome-design sampler housing, which is a simplified version of the two inverted bowl housing, where only the top bowl was used. 


\subsection{Active Air Sampling}

Active sampling was performed with a high volume sampler (TE-PNY-1123, Tisch Environmental, USA), equipped with a $20 \times 25 \mathrm{~cm}$ glass fiber filter (GFF, Whatman, Piscataway, NJ, USA; precombusted overnight at $450{ }^{\circ} \mathrm{C}$ ) and two polyurethane foam (10 x $8 \mathrm{~cm}$ diameter). Polyurethane foam (PUF, Tisch Environmental, Cleves, OH, USA) plugs were precleaned using a Dionex ASE 350 (Dionex Corporation, Sunnyvale, CA 94088) accelerated solvent extraction device. Six samples were collected at 3-4 days interval, which represent the deployment time for the co-deployed LDPEs.

\subsection{Extraction of LDPEs and PUFs}

LDPEs were cold extracted twice in DCM and n-hexane for 24 hours each after spiking with $10 \mu \mathrm{L}$ of a surrogate standard mixture composed of labeled OCPs, PCBs and PBDEs $\left({ }^{13} \mathrm{C}_{6}\right.$-hexachlorobenzene, ${ }^{13} \mathrm{C}_{12}$-p,p'-DDT, ${ }^{13} \mathrm{C}_{12}$ PCB 8, 28, 52, 118, 138, 180, 209 and ${ }^{13} \mathrm{C}_{12}$ BDE $28,47,99,153,183 ; 4 \mathrm{ng} / \mu \mathrm{L}$ in nonane). Extracts were concentrated to $\sim 1$ $\mathrm{mL}$ on a rotary evaporator, solvent exchanged to hexane, and concentrated to $\sim 25 \mu \mathrm{L}$. Ten $\mu \mathrm{L}$ of 2,4,6-tribromobiphenyl ( $5 \mathrm{ng} / \mu \mathrm{L})$, were added as an injection standard before analysis.

PUF samples were extracted using a Dionex ASE 350 (Dionex Corporation, Sunnyvale, CA 94088) accelerated solvent extraction device after spiking with the surrogate standard mixture similar to the LDPE. Extracts were concentrated to a final volume of $\sim 1 \mathrm{~mL}$ using a rotary evaporator (after solvent exchange into hexane) and passed through a silica gel cartridge (Agilent AccuBOND ${ }^{\mathrm{II}}$ ) as a cleanup step. The collected fraction was 
concentrated to a final volume of $\sim 25 \mu \mathrm{L}$. Finally, 2,4,6-tribromobiphenyl was added as the injection standard before analysis.

\subsection{Instrumental Analysis and Quality Control}

OCPs, PCBs and PBDEs were analyzed separately using an Agilent GC 6890N with a DB-5 MS fused silica capillary column $(30 \mathrm{~m} \times 0.25 \mathrm{~mm}$ i.d., $0.25 \mu \mathrm{m}$ film thickness, J\&W Scientific) equipped with a Quattro micro GC tandem MS (Waters). A total of 25 different OCPs ( p,p'-DDE, o,p'-DDD, p,p'-DDD, o,p'-DDT and p,p'-DDT, $\alpha-, \beta-, \gamma$ - and $\delta$ - $\mathrm{HCH}$, trans- and cis-chlordane, oxychlordane, trans-nonachlor, heptachlor and its epoxide, aldrin, dieldrin, endosulfan I and II, endosulfan sulfate, hexachlorobenzene, endrin, endrin aldehyde, endrin ketone and methoxychlor), 29 PCB congeners (8, 11, 18, $28,44,52,66,77,81,101,105,114,118,123,126,128,138,153,156,157,167,169$, 170, 180, 187, 189, 195, 206 and 209) and 12 PBDE congeners (2, 8, 15, 28, 30, 47, 49, 99, 100, 153, 154 and 183) were quantified using the internal standard method. More details on the instrumental analysis are given in text (SI 2).

Procedural blanks, field blanks, matrix spikes and duplicate samples were included with each sample batch, and were carried throughout the entire analytical procedure in a manner identical to the samples. POPs were completely absent from procedural and field blanks indicating contamination was negligible during transport, storage and analysis. Limits of detection (LODs) were determined as the concentration of analytes in a sample giving a peak with a signal-to-noise $(\mathrm{S} / \mathrm{N})$ of $3^{25}$. (QA/QC procedures are detailed in text SI 3). Surrogate recoveries generally ranged from $71 \%$ to $102 \%$ (Text SI 3). Results were corrected for surrogate recoveries. 


\subsection{Calculations}

\subsubsection{Adjustments for disequilibrium using PRCs}

PRCs were used to gauge whether POPs had achieved equilibrium and to adjust for disequilibrium in polyethylene $\left(\mathrm{C}_{\mathrm{LDPE}}\right)$ assuming that uptake and elimination rates are equivalent ${ }^{26}$. The $\%$ equilibrium was calculated for each of the four used PRCs (Table SI 2) as:

$$
\% \text { equilibrium }=\left(\frac{\mathrm{C}_{\mathrm{PRC}}^{0}-\mathrm{C}_{\mathrm{PRC}}^{\mathrm{t}}}{\mathrm{C}_{\mathrm{PRC}}^{\mathrm{t}}}\right) \cdot 100
$$

To adjust PE concentrations of POPs for disequilibrium, an exponential relationship was determined between \% equilibrium of the four used PRCs and $\log \mathrm{K}_{\mathrm{OA}}$ to derive $\%$ equilibrium values for all the detected POPs. Internally consistent (adjusted for thermodynamic consistency) physico-chemical properties were chosen as far as possible for the investigated POPs (see text SI 4 and Tables SI 3-6 for more details).

\subsubsection{Estimation of the sampler-air partitioning coefficients $\left(\mathrm{K}_{\mathrm{PE}-\mathrm{A}}\right)$ and temperature adjustments}

$\mathrm{K}_{\mathrm{PE}-\mathrm{A}}(\mathrm{L} / \mathrm{kg})$ values were calculated from the gaseous atmospheric concentrations $\left(\mathrm{C}_{\mathrm{g}}\right.$, $\mathrm{ng} / \mathrm{L})$ and the disequilibrium-corrected LDPE concentrations $\left(\mathrm{C}_{\mathrm{LDPE}}, \mathrm{ng} / \mathrm{kg} \mathrm{PE}\right)$ as shown in equation SI 3. Partition coefficients were adjusted for temperature according to a modified form of Van't Hoff equation (equation 2):

$$
\mathrm{K}_{\text {PE-A }}\left(\mathrm{T}_{2}\right)=\mathrm{K}_{\text {PE-A }}\left(\mathrm{T}_{1}\right) \times \mathrm{e} \frac{-\Delta \mathrm{H}_{\mathrm{vap}}}{\mathrm{R}}\left(\frac{1}{\mathrm{~T}_{2}}-\frac{1}{\mathrm{~T}_{1}}\right)
$$


where $T_{2}$ and $T_{1}$ are the mean temperatures of the deployment and at which the partitioning properties were determined $(\mathrm{K})$.

\subsubsection{Uncertainty associated with $K_{\mathrm{PE}-\mathrm{A}}$ calculations}

Calculated overall uncertainty combined the uncertainty of: (i) predicted partition coefficients, (ii) equilibrium adjustment of polyethylene concentrations based on the use of PRCs (the fraction equilibration remaining at time of PE sampler collection), and (iii) the uncertainty associated with the analysis of POPs. $\mathrm{K}_{\mathrm{PE}-\mathrm{A}}$ values for undetected POPs $(\beta-\mathrm{HCH}, \quad \delta-\mathrm{HCH}, \quad$ dieldrin, o,p'-DDD, endrin, endrin aldehyde, endrin ketone, methoxychlor, PCB 206, PCB 209, BDE 100, BDE 99, BDE 153, BDE 154 and BDE 183 ) in the field study were predicted from a simple linear relationship with $\mathrm{P}_{\mathrm{L}}$ and $\mathrm{K}_{\mathrm{OA}}$ (see section 3.3, equations 7 and 8). Accordingly, we used the same relative uncertainties (RU) in predicted $\mathrm{K}_{\mathrm{PE}^{-} \mathrm{A}} \mathrm{S}$ as given for the $\log \mathrm{P}_{\mathrm{L}}$ and $\log \mathrm{K}_{\mathrm{OA}}{ }^{27-29}$. The highest uncertainty estimate of $\mathrm{P}_{\mathrm{L}}$ in each POP group was assigned (OCPs: 69 \%; PCBs: 38 \%; PBDEs: 20 $\%$ ) for $\mathrm{P}_{\mathrm{L}}$ values that were not internally consistent (see text SI 4). The same process was applied to $\mathrm{K}_{\mathrm{OA}}$ (see Tables SI 7-9 for more details). The overall uncertainty ranged from $\pm 8.0 \%$ to $\pm 105 \%(0.04-0.5 \log$ units $)$ when $\mathrm{P}_{\mathrm{L}}$ was used as a predictor of $\mathrm{K}_{\mathrm{PE}-\mathrm{A}}$ and 8.0$171 \%\left(0.04-0.8 \log\right.$ units) when $\mathrm{K}_{\mathrm{OA}}$ was used.

\section{3- Results and discussion}

\subsection{Uptake rate study}

We used two approaches to characterize uptake kinetics: collecting samplers at different time points during the exposure period (21 days; approach 1), and the use of PRCs (approach 2). 


\subsubsection{Accumulation trends of POPs in LDPE (approach 1)}

15 OCPs, 27 PCB congeners and 7 PBDE congeners were quantified in the passive samplers (Tables SI 10- SI 12). Accumulation profiles of some selected POPs are shown in Figure (1). Hexachlorobenzene, $\alpha$ - and $\gamma$-HCHs, heptachlor, PCB 8, 11, 18, 28, 52, 44 and $\mathrm{BDE} 2\left(\log \mathrm{K}_{\mathrm{OA}}: 7.10-8.38\right)$ were approaching equilibrium after the 21 days deployment period (Figure 1A). Profiles of this group started to deviate from the linear phase after 14 days (20-11 to 4-12, 2012) although elevated gaseous concentrations $\left(C_{g}\right)$ were observed in the period from December 4-11, 2012 (Tables SI 13-SI 15). All the other detected POPs (penta - octa PCBs, di - tetra PBDEs, endosulfans, DDTs, chlordanes and endosulfan sulfate) were still in the linear uptake phase (Figure 1B). Starting from December 4 to 11, 2012, there was an observed increase in the uptake of POPs (Figure 1B) in this group compared to the first two weeks (November 20 to December 4, 2012). This increase corresponded to the observed elevated gaseous air concentrations measured by the high volume sampler. However, for some OCPs (chlordanes, endosulfans, p,p'-DDD, p,p'-DDE), we observed a decrease in the uptake during the last deployment period (7-11/12/2012). This was a reflection of lower gaseous concentrations of these OCPs (Table SI 13) compared to the previous sampling period.

\subsubsection{Uptake stage indication using PRCs (approach 2)}

Spiking of samplers with PRCs before deployment is useful to infer the exchange rate kinetics, assuming that the elimination rates (of PRCs) and uptake rates (of native compounds) are equivalent ${ }^{26}$. Exchange kinetics were quantified by $\mathrm{k}_{\mathrm{e}}$. 

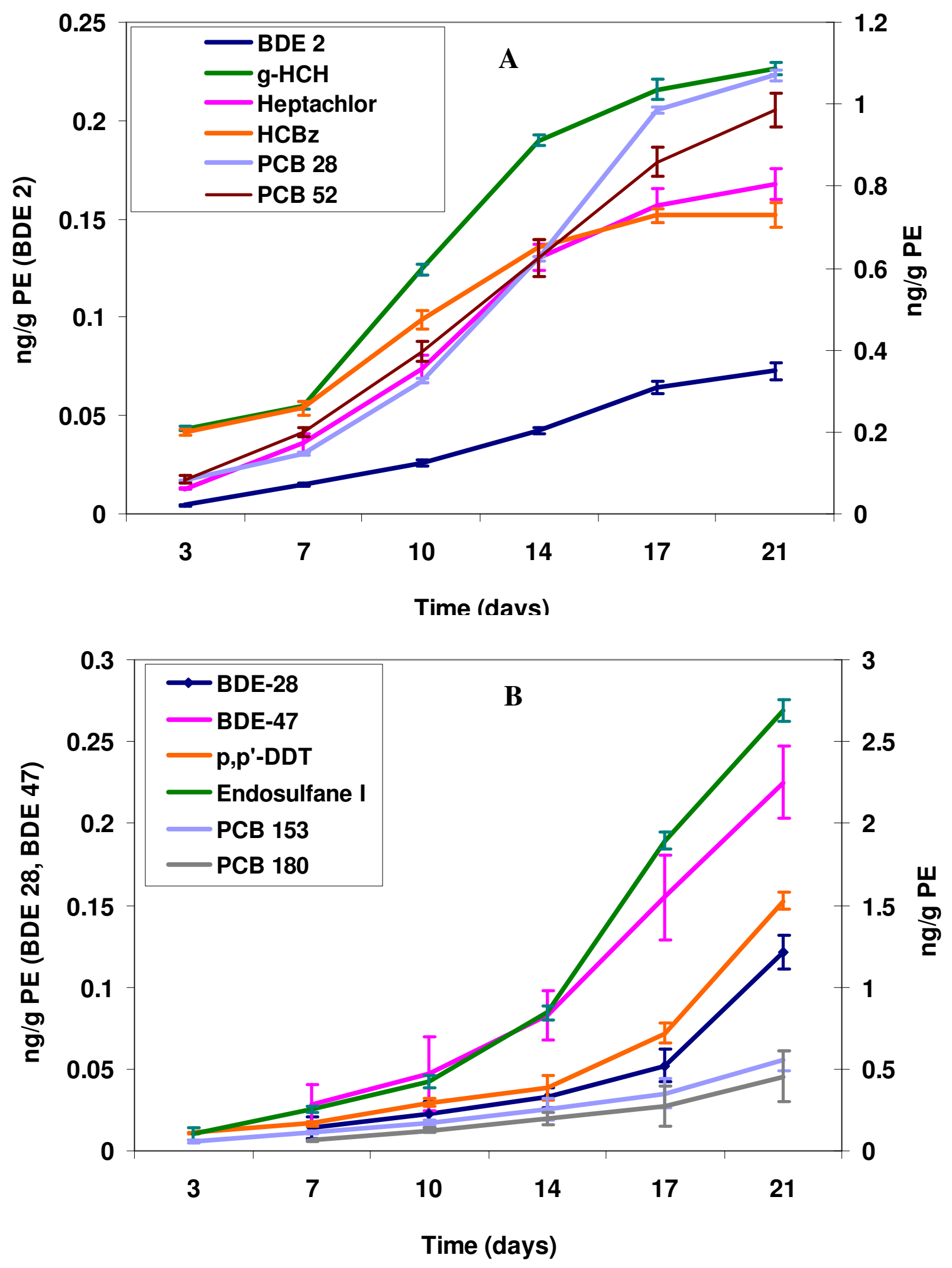

Figure 1: Accumulation patterns of POPs (ng/g PE) during the deployment period. Error bars represent the standard deviation of the replicates. 
Four PRCs with different $\log \mathrm{K}_{\mathrm{OA}}$ values were used in this study to derive exchange kinetics (see section 2.7.1). The least dissipated PRC in all samples was octachloronaphthalene $(\mathrm{OCN})$, and $\mathrm{k}_{\mathrm{e}}$ generally decreased with increasing $\log \mathrm{K}_{\mathrm{OA}}(\mathrm{OCN}$ $<$ PBB $103<$ PBB $52<$ PBB 9).

Average values of $\%$ equilibrium approached by the investigated POPs at each time period are given in Tables (SI 16-18). Profiles of some selected POPs are shown in Figure (2). Hexachlorobenzene, $\alpha$ - and $\gamma$-HCHs, heptachlor, PCB 8, 11, 18, 28, 52, 44 and BDE 2 were at or approaching equilibrium by the end of the deployment period ( $>90$ \%) (Figure 2A). All the other POPs (Figure 2B) were still away from reaching equilibrium $(<50 \%)$; much longer deployment times are required for them to equilibrate. To compare approaches (1) and (2), \% equilibrium results of OCPs based on the PRCs were compared to $\%$ equilibrium values derived from $\mathrm{C}_{\mathrm{LDPE}}$ and measured $\mathrm{C}_{\mathrm{g}}$. This was calculated as (equation 3):

$$
\% \text { equilibrium }=\left(\frac{C_{\mathrm{LDPE}(\text { nonequilibrium) }}}{\mathrm{C}_{\mathrm{LDPE}(\text { equilibrium })}}\right) \cdot 100
$$

where $\mathrm{C}_{\mathrm{LDPE}(\text { nonequilibrium) }}$ is the compound's disequilibrium uncorrected concentration in the LDPE (ng/kg PE) and $\mathrm{C}_{\mathrm{LDPE}(\text { equilibrium) }}$ is the compounds concentration in the PE at equilibrium. $\mathrm{C}_{\mathrm{LDPE}(\text { equilibrium) }}$ was calculated as (equation 4):

$$
\mathrm{C}_{\text {LDPE(equilibrium) }}=\mathrm{K}_{\text {PE-A }} \cdot \mathrm{C}_{\mathrm{g}}
$$

$\mathrm{K}_{\mathrm{PE}-\mathrm{A}}$ values for OCPs were taken from Khairy and Lohmann ${ }^{6}$. This step was not performed for PCBs and PBDEs as no field based $\mathrm{K}_{\mathrm{PE}-\mathrm{A}}$ values exist in literature. 

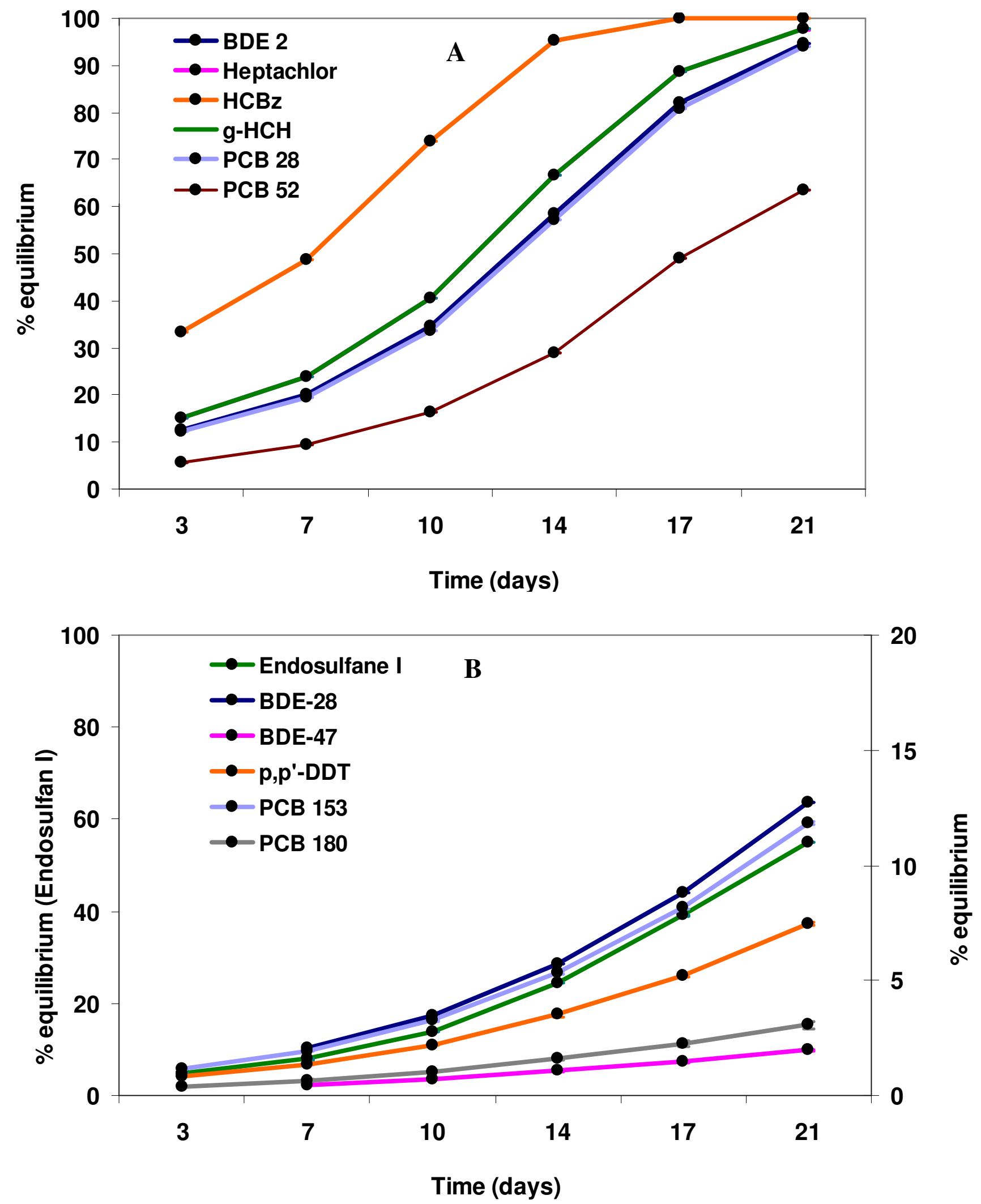

Figure 2: \% equilibrium of the accumulated POPs based on the dissipation rates of the PRCs during the deployment period. 
As shown in Figure (3), good agreement was generally observed between both approaches $\left(\mathrm{R}^{2}=0.99, \mathrm{p}<0.001\right)$. This implies that PRCs can be used to calibrate sampler/site specific mass transfer behavior, and thus accurately estimate the gaseous concentrations of POPs in the atmosphere.

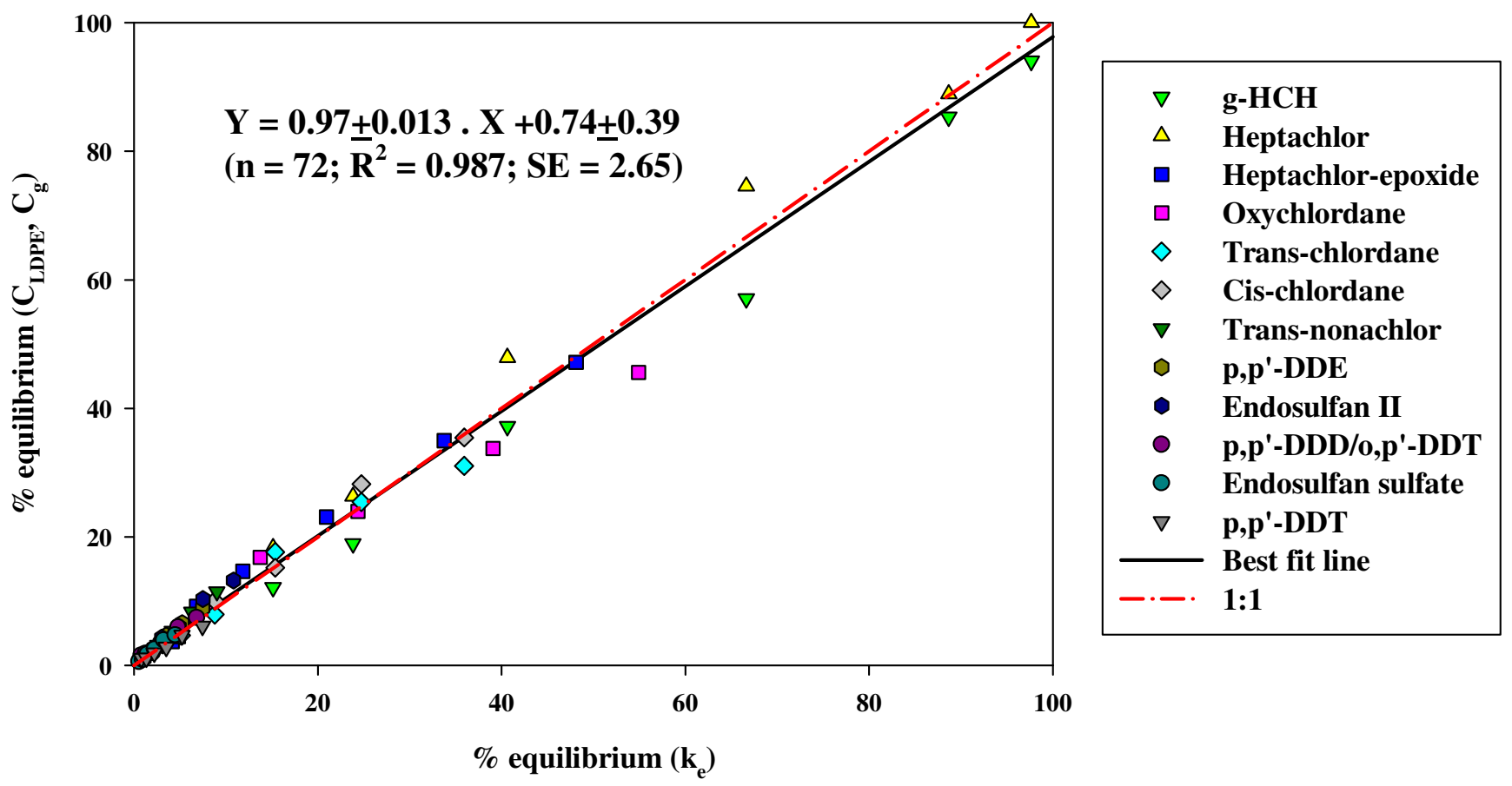

Figure 3: Comparison between calculated \% equilibrium of OCPs using approach (1) and approach (2). \% equilibrium $\left(\mathrm{k}_{\mathrm{e}}\right)$ is calculated as shown in section $2.7 .1 ; \%$ equilibrium $\left(\mathrm{C}_{\mathrm{LDPE}}, \mathrm{C}_{\mathrm{g}}\right)$ is calculated from equations 3 and 4 .

\subsubsection{Sampling rates $\left(\mathbf{R}_{\mathbf{s}}\right)$}

Sampling rates $\left(\mathrm{R}_{\mathrm{s}}\right)$ for investigated POPs were calculated as shown in equation 5:

$$
\mathrm{R}_{\mathrm{s}}\left(\mathrm{m}^{3} / \mathrm{d}\right)=\frac{\mathrm{C}_{\mathrm{LDPE}}}{\mathrm{K}_{\mathrm{PE}-\mathrm{A}} \cdot \mathrm{t}}
$$

Calculated sampling rates are given in Tables (SI 19-21). Sampling rates ranged from 1.0-28 $\mathrm{m}^{3} / \mathrm{d}$ for OCPs (except endosulfan I and p,p'-DDT), di - tetra chlorinated 
biphenyls and mono - tri brominated diphenyl ethers. These values were within and/or slightly higher than the range calculated for PAHs and PCBs in literature ${ }^{21,22,26} \cdot \mathbf{R}_{s}$ ranged from 4.7-35 $\mathrm{m}^{3} / \mathrm{d}$ for endosulfan I and p,p'-DDT, 10-80 $\mathrm{m}^{3} / \mathrm{d}$ for penta- octa chlorinated biphenyls, and $34-59 \mathrm{~m}^{3} / \mathrm{d}$ tetra brominated diphenyl ethers. These values were much higher than literature values for PCBs and PAHs ${ }^{21,22,26}$. Higher sampling rates were expected in the current study as the LDPE sheets were deployed in a dome-design sampler housing with only the top bowl. This indeed caused an increase in the air velocity inside the housing and thus higher uptake rates.

We also estimated the average sampling rate by the nonlinear least square method according to Booij and Smedes ${ }^{30}$. This approach depends on the dissipation rates of all the used PRCs even if they were close to 0 or 1 . The retained fraction of PRCs $(f)$ is expressed as a continuous function of $\mathrm{K}_{\mathrm{OA}}$ (or $\mathrm{K}_{\mathrm{PE}-\mathrm{A}}$ ) with $\mathrm{R}_{\mathrm{S}}$ as an adjustment parameter. In the current study, we used \% equilibrium instead of $f$ as shown in equation 6:

$$
\% \text { equilibrium }=\left(1-\exp \left(\frac{-\mathrm{R}_{\mathrm{s}} \cdot \mathrm{t}}{\mathrm{K}_{\mathrm{OA}} \cdot \mathrm{V}_{\mathrm{LDPE}}}\right)\right) \cdot 100
$$

where, $\mathrm{t}$ is the deployment period (days), and $\mathrm{V}_{\mathrm{LDPE}}$ is the volume of the LDPE $\left(\mathrm{m}^{3}\right)$. Initially, a random $R_{s}$ value was chosen and \% equilibrium was calculated for all the investigated analytes using equation 6 . These values were compared to the \% equilibrium values calculated as shown in section 2.6.1 using a nonlinear least square model. Accordingly, the random $R_{s}$ value used was automatically adjusted such that the least square difference between calculated \% equilibrium values (using the 2 different approaches) was achieved. 
Average $R_{s}$ ranged from $5.6 \mathrm{~m}^{3} / \mathrm{d}$ (0-3 days) to $20 \mathrm{~m}^{3} / \mathrm{d}$ (0-21 days). Average sampling rates calculated using equation 5 for the same deployment periods were $\sim 2$ folds higher $\left(14 \mathrm{~m}^{3} / \mathrm{d}, 37 \mathrm{~m}^{3} / \mathrm{d}\right)$. Passive sampling theory indicated that the uptake from the atmosphere to the passive samplers occurs predominantly via the gaseous phase. Most of the lighter OCPs, lower chlorinated PCBs and lower brominated PBDEs occur predominantly in the gaseous phase, while most of the higher chlorinated $(5-8 \mathrm{Cl})$ and brominated (4-7 Br) PCB and PBDE congeners are bound to atmospheric particulates. Accordingly, particle deposition to the passive samplers could increase the uptake rate for compounds that are still in the linear uptake phase if they adhere to the surface of the $\mathrm{LDPE}^{7}$. In the current study, POPs with $\log \mathrm{K}_{\mathrm{OA}}>9$ existed mainly in the particulate phase $(>70 \%$ of the gas + particle concentrations). For this group, sampling rates (Figure 4) decreased significantly (at $p<0.001$ ) if the calculation was based on the particulate + gaseous phase concentrations. If particulate + gaseous phase concentrations were used, average sampling rates were $4.2 \mathrm{~m}^{3} / \mathrm{d}$ and $15 \mathrm{~m}^{3} / \mathrm{d}$ for the first (0-3 days) and the last (0-21 days) deployment periods respectively. These new average values were very close to those calculated using equation 6 . However, the assumption that uptake could occur from surface adhering particles was never investigated for LDPE and thus, further investigation is required to determine the significance of this process.

\subsection{Sampler-air partitioning coefficients $\left(\mathrm{K}_{\mathrm{PE}-\mathrm{A}}\right)$}

PE-A partitioning constants were calculated for POPs as shown in equation SI 3 (Tables SI 22-24). Calculated $\mathrm{K}_{\mathrm{PE}-\mathrm{A}}$ values for all quantified POPs were at or below their corresponding $\mathrm{K}_{\mathrm{OA}}$ values (Tables SI 2, 3 and 4). Calculated $\mathrm{K}_{\mathrm{PE}-\mathrm{A}}$ values of OCPs in the current study were compared to values reported by Khairy and Lohmann ${ }^{6}$. 


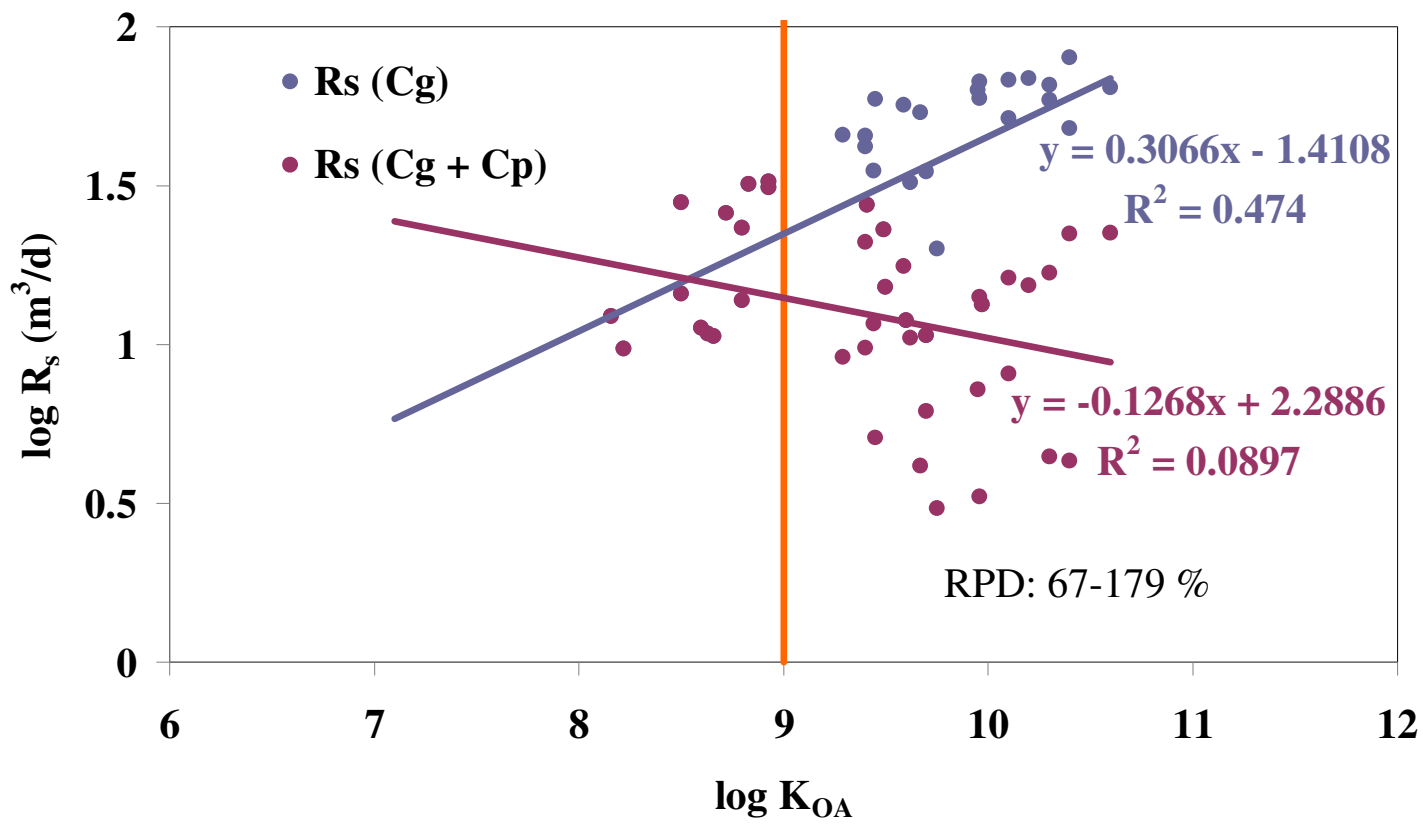

Figure 4: Plot of $\log \mathrm{K}_{\mathrm{OA}}$ vs sampling rates $\left(\mathrm{R}_{\mathrm{s}}\right)$ of POPs showing the difference when gaseous concentrations $\left(\mathrm{C}_{\mathrm{g}}\right)$ or gaseous + particle concentrations $\left(\mathrm{C}_{\mathrm{g}}+\mathrm{C}_{\mathrm{p}}\right)$ are used for $\mathrm{R}_{\mathrm{s}}$ calculations for analytes with $\log \mathrm{K}_{\mathrm{OA}}>9$.

On average, values from both studies differed by only $39 \%$ (range 9-64\%, see Table SI 22). $\mathrm{K}_{\mathrm{PE}-\mathrm{A}}$ values of PCBs (Table SI 23) and PBDEs (Table SI 24) were compared to $\mathrm{K}_{\mathrm{PE}-}$ A values calculated from $\mathrm{K}_{\mathrm{PE}-\mathrm{W}}$ and $\mathrm{K}_{\mathrm{AW}}$. Similar to OCPs, good agreement (difference of 0.01-0.3 log units) was observed for the majority of PCB (3-74 \%) and PBDE congeners (32-77\%). Lower degree of agreement was observed for PCB 187 and 195 (0.5-0.6 log units) and BDE 2 (0.5 log unit). Nevertheless, all differences observed for POPs were still within the overall calculated uncertainty (Tables SI 7-9). This in terms supports the assumption that our field-derived $\mathrm{K}_{\mathrm{PE}-\mathrm{A}}$ values are good approximations of their real values. 


\subsection{Correlation of $K_{P E-A}$ with $P_{L}$}

We investigated $\mathrm{P}_{\mathrm{L}}$ as a predictor for $\mathrm{K}_{\mathrm{PE}-\mathrm{A}} \mathrm{S}$ of POPs in the current study. When $\mathrm{P}_{\mathrm{L}}$ was used as the predictor, a strong linear $\mathrm{K}_{\mathrm{PE}-\mathrm{A}}-\mathrm{P}_{\mathrm{L}}$ relation was observed separately for OCPs, PCBs, PBDEs (this study) and PAHs (taken from the literature, 5). This correlation explained $97 \%, 98 \%, 96 \%$ and $97 \%$ respectively of the total variability in the data in each class of pollutants. This indicates that $\mathrm{P}_{\mathrm{L}}$ is a good predictor of $\mathrm{K}_{\mathrm{PE}^{-} \mathrm{A}} \mathrm{S}$ for individual compound groups. A significant and strong correlation was observed when $\mathrm{K}_{\mathrm{PE}-\mathrm{A}} \mathrm{S}$ of all POPs were regressed against $\mathrm{P}_{\mathrm{L}}(\mathrm{Pa})(\mathrm{p}<0.001)$ (Figure 5A; equation 7):

$$
\begin{aligned}
& \log \mathrm{K}_{\mathrm{PE}-\mathrm{A}}=-0.82 \pm 0.02 \cdot \log \mathrm{P}_{\mathrm{L}}+6.22 \pm 0.05 \\
& \left(\mathrm{n}=59 ; \mathrm{R}^{2}=0.96 ; \mathrm{SE}=0.22\right)
\end{aligned}
$$

The correlation explained $96 \%$ of the total variability in the data. The slope was insignificantly different from $-1\left(p<0.001 ; R^{2}=0.97\right)$, implying that $P_{L}$ can be used as a good predictor of $\mathrm{K}_{\mathrm{PE}-\mathrm{A}}$, and that the magnitude of $\mathrm{K}_{\mathrm{PE}-\mathrm{A}}$ for POPs is dominated by their volatilities. Accordingly, $\mathrm{K}_{\mathrm{PE}-\mathrm{A}}$ values for the non-quantified POPs in the passive sampler were predicted (Tables SI 22-24) based on the derived $\mathrm{P}_{\mathrm{L}}-\mathrm{K}_{\mathrm{PE}-\mathrm{A}}$ relation.

\subsection{Correlation of $K_{P E-A}$ with $K_{O A}$}

We also examined the correlation between the $\mathrm{K}_{\mathrm{PE}-\mathrm{A}} \mathrm{S}$ derived here, including those for PAHs that were reported previously ${ }^{5}$, and $\mathrm{K}_{\mathrm{OA}}$. As shown in Figure (5B), a highly significant and strong linear correlation can be observed for all POPs $\left(\mathrm{R}^{2}=0.96\right.$, $\mathrm{p}<0.001$ ) (equation 8):

$$
\begin{aligned}
& \log \mathrm{K}_{\mathrm{PE}-\mathrm{A}}=0.88 \pm 0.02 \cdot \log \mathrm{K}_{\mathrm{OA}}+0.4 \pm 0.21 \\
& \left(\mathrm{n}=59 ; \mathrm{R}^{2}=0.96 ; \mathrm{SE}=0.23\right)
\end{aligned}
$$



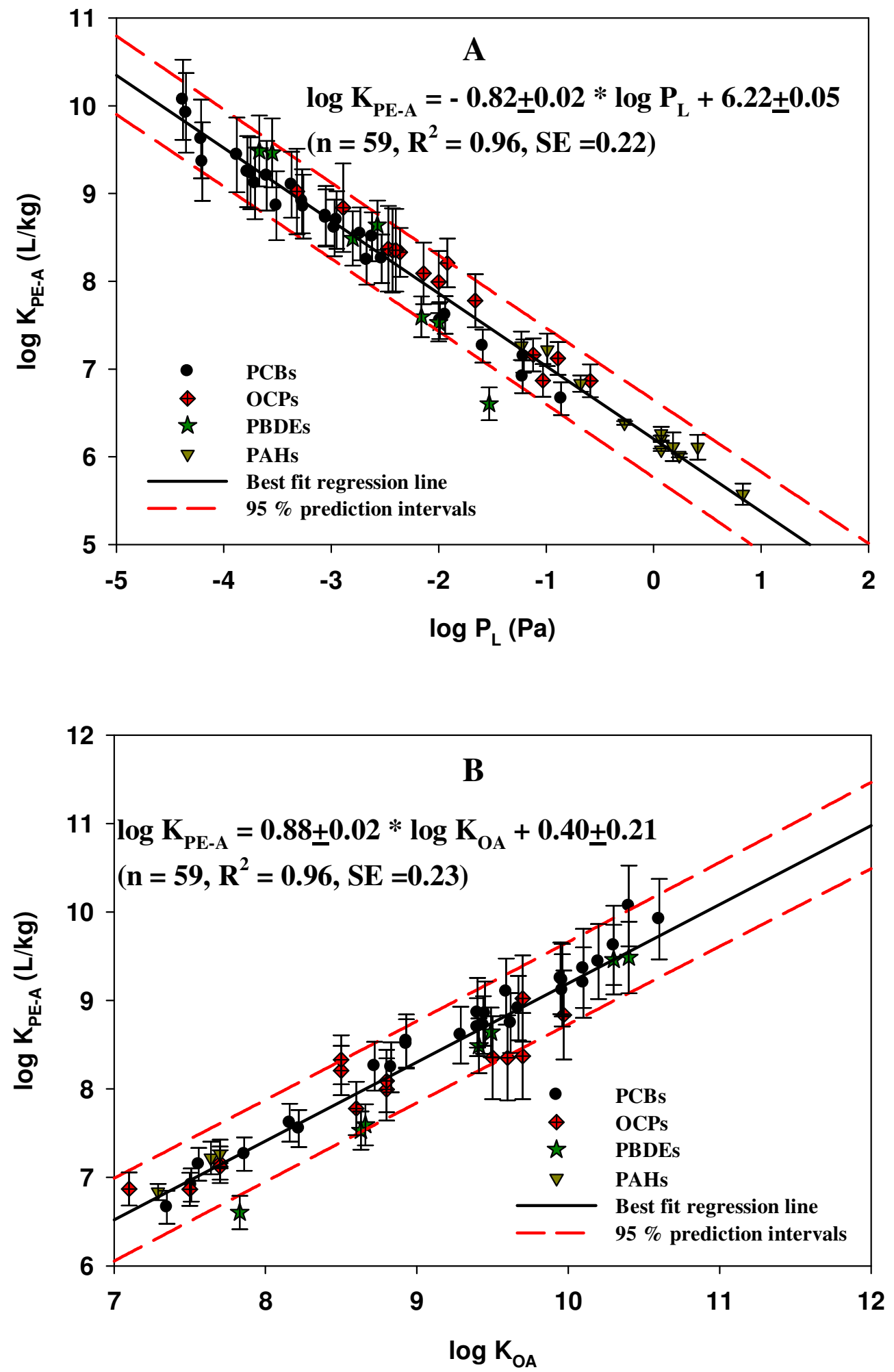

Figure 5: Best fit model of $\log \mathrm{K}_{\mathrm{PE}-\mathrm{A}}$ versus $\log \mathrm{K}_{\mathrm{OA}}(\mathrm{A})$ and $\log \mathrm{P}_{\mathrm{L}}(\mathrm{B})$ for POPs. Error bars represent the relative uncertainty. Dashed lines represent the $95 \%$ prediction intervals. PAHs are taken from reference 5. 
The slope of this relation was insignificantly different from $1(\mathrm{p}<0.001)$, whereas the intercept was significantly different from zero $(\mathrm{p}>0.05)$. This indicates that $\mathrm{K}_{\mathrm{OA}}$ can be used as a good predictor for $\mathrm{K}_{\mathrm{PE}-\mathrm{A}}$ of POPs. For further assessment, the significance of the $\mathrm{K}_{\mathrm{PE}-\mathrm{A}}-\mathrm{K}_{\mathrm{OA}}$ relation was evaluated for each class of POPs separately. A highly significant strong relation was observed for PCBs, PBDEs and PAHs $\left(\mathrm{R}^{2}>0.97, \mathrm{p}<\right.$ 0.001). However, the degree of $\mathrm{K}_{\mathrm{PE}-\mathrm{A}}-\mathrm{K}_{\mathrm{OA}}$ relation was lower for OCPs and the regression line explained $87 \%$ of the total variability in the OCP data.

In our previous work ${ }^{6}$, the $\mathrm{K}_{\mathrm{PE}^{-} \mathrm{A}^{-}} \mathrm{K}_{\mathrm{OA}}$ relation for OCPs explained only $32 \%$ of the total variability in the data, and it was not suitable to use $\mathrm{K}_{\mathrm{OA}}$ as predictors for $\mathrm{K}_{\mathrm{PE}-\mathrm{A}}$. This difference in the degree of relation is attributed to the investigated OCPs. In the current study. aldrin, o,p'-DDD, endrin, endrin aldehyde and endrin ketone were not detected in the samples. This implies that the significance of the $\mathrm{K}_{\mathrm{PE}-\mathrm{A}}-\mathrm{K}_{\mathrm{OA}}$ relation for OCPs varies according to the investigated OCPs which could result in a higher degree of uncertainty in predicted $\mathrm{K}_{\mathrm{PE}-\mathrm{A}}$ values.

\subsection{Prediction of $\mathrm{K}_{\mathrm{PE}-\mathrm{A}}$ for other POPs}

Based on our results, the derived $\mathrm{K}_{\mathrm{PE}-\mathrm{A}}-\mathrm{P}_{\mathrm{L}}$ relation is a good general approach to predict $\mathrm{K}_{\mathrm{PE}-\mathrm{A}}$ values for apolar and monopolar organic compounds. Accordingly, we predicted $\mathrm{K}_{\mathrm{PE}-\mathrm{A}}$ values for PAHs (Table SI 25), dioxins and furans (Table SI 26) using equation 7. Predicted PAH values were compared with $\mathrm{K}_{\mathrm{PE}-\mathrm{A}} \mathrm{S}$ obtained from Khairy and Lohmann ${ }^{5}$. Dioxin values were compared to $\mathrm{K}_{\mathrm{PE}-\mathrm{A}}$ values calculated from $\mathrm{K}_{\mathrm{PE}-\mathrm{W}}$ and $\mathrm{K}_{\mathrm{AW}}$ (Table $\mathrm{SI}$ 26). Good agreement was generally observed between predicted $\mathrm{K}_{\mathrm{PE}-\mathrm{A}}$ values for PAHs using our $\mathrm{K}_{\mathrm{PE}-\mathrm{A}}-\mathrm{P}_{\mathrm{L}}$ relation and those obtained from reference 5. Similarly, $\mathrm{K}_{\mathrm{PE}-\mathrm{A}}$ values 


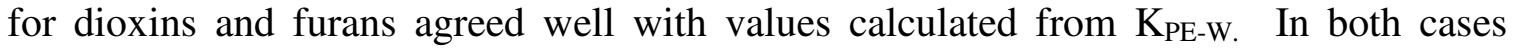
(average $\%$ difference: $55 \%$ ), \% difference ranged from 2.6-130\% (0.01-0.6 log units). This implies that equation 7 can be successfully used to predict $\mathrm{K}_{\mathrm{PE}-\mathrm{A}}$ values for apolar organic pollutants not included in the current field calibration study.

\section{4- Conclusions}

In recent years, LDPE sheets have increasingly been utilized as passive samplers for monitoring atmospheric concentrations of POPs. However, field calibration of LDPE was only performed for PAHs and OCPs, and sampler-air partitioning coefficients $\left(\mathrm{K}_{\mathrm{PE}-\mathrm{A}}\right)$ are not available for the other classes of POPs. Accordingly, a field calibration study was done to validate LDPE as passive air samplers for POPs. Our results indicated the feasibility of using LDPE as a practical and low-cost technique for monitoring gas-phase POPs. Field validated $\mathrm{K}_{\mathrm{PE}-\mathrm{A}}$ values were calculated for 15 OCPs, 27 PCB congeners and 7 PBDE congeners. A strong linear $\mathrm{K}_{\mathrm{PE}-\mathrm{A}}-\mathrm{P}_{\mathrm{L}}$ relationship was derived:

$$
\log _{\text {PE-A }}=-0.82 \pm 0.02 \cdot \log \mathrm{P}_{\mathrm{L}}+6.22 \pm 0.05
$$

$\left(\mathrm{R}^{2}=0.96 ; \mathrm{p}<0.001\right)$. Predicted $\mathrm{K}_{\mathrm{PE}-\mathrm{A}} \mathrm{S}$ for OCPs, PAHs, PCBs, PBDEs, dioxins and furans from this equation agreed well with published $\mathrm{K}_{\mathrm{PE}-\mathrm{A}}$ values (Khairy and Lohmann $^{5,6}$ ) for PAHs and OCPs (average $\%$ difference: $9 \%$ and $48 \%$ respectively), and with values predicted from $\mathrm{K}_{\mathrm{PE}-\mathrm{W}}$ and $\mathrm{K}_{\mathrm{AW}}$ for the other POPs (44\% for PCBs, $104 \%$ for PBDEs and $52 \%$ for dioxins and furans). Accordingly, our proposed $\mathrm{K}_{\mathrm{PE}-\mathrm{A}^{-}} \mathrm{P}_{\mathrm{L}}$ relation can accurately predict $\mathrm{K}_{\mathrm{PE}-\mathrm{A}}$ values for apolar organic compounds even those not included in the current study. This could increase the utilization of LDPE as passive air samplers. 
Our results indicated that the use of PRCs (approach 2) is useful in the characterization of the uptake kinetics. Using PRCs could potentially reduce the number of deployed passive samplers compared to the collection of passive samplers at various time points during the exposure period approach and the deployment of LDPEs with different surface area-tovolume ratio approach. Our results suggest that PEs up to $51 \mu \mathrm{m}$ thin can be used as equilibrium samplers for POPs with $\log \mathrm{K}_{\mathrm{PE}-\mathrm{A}} \mathrm{S} \leq 7.6$ while deployed for a few weeks. For POPs with $\log \mathrm{K}_{\mathrm{PE}-\mathrm{A}} \mathrm{S} \geq 8.0$ a deployment period of $1-2$ months would be more appropriate based on the dissipation rates of the PRCs. Future work should investigate the significance of particle deposition on LDPE samplers with respect to POPs exchange.

\section{Supplementary information}

Supplementary data associated with this article can be found in the online version.

\section{Acknowledgment}

Authors would like to thank Mr. Dave Adelman (GSO, URI) for his effort in PE preparation and in the sampling process. Dr. Mohammed Khairy acknowledges the Fulbright Foundation for offering him the opportunity to carry this research in USA. Dr. Rainer Lohmann acknowledges funding from EPA's Great Lakes Restoration Initiative Award GLAS \# 00E00597-0 supporting passive sampler research at URI.

\section{5- References}

1. F. Wania, L. Shen, Y. D. Lei, C. Teixeira and D. C. G. Muir, Environmental Science \& Technology, 2003, 37, 1352-1359.

2. L. Tuduri, T. Harner and H. Hung, Environmental Pollution, 2006, 144, 377-383.

3. C. Chaemfa, J. L. Barber, T. Gocht, T. Harner, I. Holoubek, J. Klanova and K. C. 
Jones, Environmental Pollution, 2008, 156, 1290-1297.

4. N. J. Farrar, K. Prevedouros, T. Harner, A. J. Sweetman and K. C. Jones, Environmental Pollution, 2006, 144, 423-433.

5. M. A. Khairy and R. Lohmann, Environmental Science \& Technology, 2012, 46, 3990-3998.

6. M. A. Khairy and R. Lohmann, Environmental Pollution, 2013, 181, 151-158.

7. M. E. Bartkow, D. W. Hawker, K. E. Kennedy and J. F. Müller, Environmental Science \& Technology, 2004, 38, 2701-2706.

8. D. Calamari, E. Bacci, S. Focardi, C. Gaggi, M. Morosini and M. Vighi, Environmental Science \& Technology, 1991, 25, 1489-1495.

9. D. C. G. Muir, M. D. Segstro, P. M. Welbourn, D. Toom, S. J. Eisenreich, C. R. Macdonald and D. M. Whelpdale, Environmental Science \& Technology, 1993, 27, 1201-1210.

10. I. Holoubek, A. Ansorgova, P. Korinek, J. Ã. Kohoutek, K. r. Staffova, Z. Paschova, I. Holoubkova and J. Ã. Mitera, Polycyclic Aromatic Compounds, 2000, 20, 67-77.

11. W. A. Ockenden, A. J. Sweetman, H. F. Prest, E. Steinnes and K. C. Jones, Environmental Science \& Technology, 1998, 32, 2795-2803.

12. R. Lohmann, B. P. Corrigan, M. Howsam, K. C. Jones and W. A. Ockenden, Environmental Science \& Technology, 2001, 35, 2576-2582.

13. T. Harner, N. J. Farrar, M. Shoeib, K. C. Jones and F. A. P. C. Gobas, Environmental Science \& Technology, 2003, 37, 2486-2493.

14. S. N. Meijer, W. A. Ockenden, E. Steinnes, B. P. Corrigan and K. C. Jones, 
Environmental Science \& Technology, 2002, 37, 454-461.

15. F. M. Jaward, S. N. Meijer, E. Steinnes, G. O. Thomas and K. C. Jones, Environmental Science \& Technology, 2004, 38, 2523-2530.

16. J. D. Petty, J. N. Huckins and J. L. Zajicek, Chemosphere, 1993, 27, 1609-1624.

17. F. M. Jaward, G. Zhang, J. J. Nam, A. J. Sweetman, J. P. Obbard, Y. Kobara and K. C. Jones, Environmental Science \& Technology, 2005, 39, 8638-8645.

18. N. L. Devi, S. Qi, P. Chakraborty, G. Zhang and I. C. Yadav, Journal of Environmental Sciences, 2011, 23, 808-815.

19. S.-Y. Baek, J. Jurng and Y.-S. Chang, Atmospheric Environment, 2013, 64, 40-46.

20. J. F. Müller, D. W. Hawker, D. W. Connell, P. Kamp and M. S. McLachlan, Atmospheric Environment, 2000, 34, 3525-3534.

21. K. E. Kennedy, D. W. Hawker, J. F. Müller, M. E. Bartkow and R. W. Truss, Atmospheric Environment, 2007, 41, 5778-5787.

22. M. E. Bartkow, K. Booij, K. E. Kennedy, J. F. Müller and D. W. Hawker, Chemosphere, 2005, 60, 170-176.

23. R. Lohmann, Environmental Science \& Technology, 2012, 46, 606-618.

24. K. Booij, F. Smedes and E. M. van Weerlee, Chemosphere, 2002, 46, 1157-1161.

25. R.-A. Doong, Y.-C. Sun, P.-L. Liao, C.-K. Peng and S.-C. Wu, Chemosphere, 2002, 48, 237-246.

26. M. E. Bartkow, K. C. Jones, K. E. Kennedy, N. Holling, D. W. Hawker and J. F. Müller, Environmental Pollution, 2006, 144, 365-370.

27. L. Shen and F. Wania, Journal of Chemical \& Engineering Data, 2005, 50, $742-$ 768. 
28. F. Wania and C. B. Dugani, Environmental Toxicology and Chemistry, 2003, 22, 1252-1261.

29. A. Aberg, M. Macleod and K. Wiberg, Journal of Physical and Chemical Reference Data, 2008, 37, 1997-2008.

30. K. Booij and F. Smedes, Environmental Science and Technology, 2010, 44, 67896794. 